\title{
Management of Gastroesophageal Reflux Disease in Asian Countries: Results of a Questionnaire Survey
}

\author{
Mariko Hojo $^{a}$ Akihito Nagahara ${ }^{a}$ Ki-Baik Hahm ${ }^{b}$ Ryuichi Iwakiric \\ Toshio Watanabe $^{d}$ Abdul Aziz Rani ${ }^{\mathrm{e}}$ Qi Zhu' ${ }^{\mathrm{f}}$ Francis K.L. Chan ${ }^{\mathrm{g}}$ \\ Jose D. Sollano ${ }^{h}$ Takeshi Kamiya ${ }^{i}$ Satoru Yamaguchi ${ }^{j}$ Satoshi Motoyak \\ Kwong Ming Fock ${ }^{l}$ Shin Fukudom ${ }^{m}$ Udom Kachintorn $^{n}$ Hidekazu Suzuki $^{\circ}$ \\ Kazunari Murakami ${ }^{p}$ The International Gastroenterology Consensus \\ Symposium Study Group
}

a Department of Gastroenterology, Juntendo University School of Medicine, Tokyo, Japan; ${ }^{b}$ Digestive Disease Center, CHA University School of Medicine and CHA University Bundang Medical Center, Seoul, South Korea; 'Deaprtment of Internalmedicine and Gastrointestinal Endoscopy, Saga Medical School, Saga, Japan; dDepartment of Gastroenterology, Osaka City University Graduate School of Medicine, Osaka, Japan; eDepartment of Internal Medicine, Faculty of Medicine, University of Indonesia Cipto Mangunkusumo Hospital,

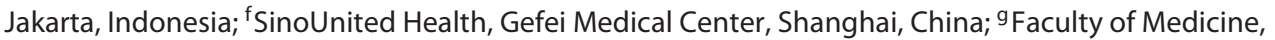
The Chinese University of Hong Kong, Hong Kong, China; hepartment of Medicine, University of Santo Tomas, Manila, Philippines; 'Department of Medical Innovation, Nagoya City University Graduate School of Medical Sciences,

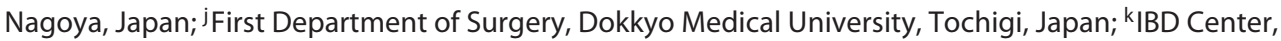
Sapporo Kosei General Hospital, Sapporo, Japan; 'Department of Gastroenterology, Changi General Hospital, Singapore, Singapore; ${ }^{m}$ Behavioral Medicine, Tohoku University Graduate School of Medicine, Sendai, Japan; ${ }^{n}$ Division of Gastroenterology, Department of Internal Medicine, Faculty of Medicine, Siriraj Hospital Mahidol University, Bangkok, Thailand; ${ }^{\circ}$ Department of Gastroenterology and Hepatology, Tokai University School of Medicine, Isehara, Japan; ${ }^{p}$ Faculty of Medicine, Oita University, Oita, Japan; ${ }^{9}$ Ruijin Hospital, Shanghai Jiaotong University School of Medicine, Shanghai, China

\section{Keywords}

Erosive gastroesophageal reflux disease $\cdot$ Nonerosive gastroesophageal reflux disease · Uninvestigated gastroesophageal reflux disease · Barrett's esophagus . Endoscopic surveillance

\begin{abstract}
Introduction: The Asia-Pacific consensus on the management of gastroesophageal reflux disease (GERD) and the GERD treatment guidelines of 2015 drawn up by the Japanese Society of Gastroenterology were proposed, and GERD management in Asian regions was assumed to be performed
\end{abstract}

\section{KARGER}

(c) 2019 S. Karger AG, Basel

E-Mail karger@karger.com

www.karger.com/dig
Akihito Nagahara

Department of Gastroenterology

Juntendo University School of Medicine

2-1-1 Hongo, Bunkyo-ku, Tokyo 113-8421 (Japan)

E-Mail nagahara@juntendo.ac.jp 
based on these consensuses. In this environment, the current status of GERD management in clinical practice among Asian regions is less well-known. Objective: This questionnaire-based consensus survey was performed to clarify the current status of management of GERD in clinical practice in Asian regions. Methods: A questionnaire related to management of GERD was distributed to members of the International Gastroenterology Consensus Symposium Study Group. We analyzed the questionnaire responses and compared the results among groups. Results: The frequencies of erosive GERD (ERD), non-ERD, uninvestigated GERD, and Barrett's esophagus varied significantly among Asian countries. The most important factor in diagnosing GERD was the presence of symptoms in all countries. A proton pump inhibitor was the most commonly prescribed drug to treat GERD in all countries. Endoscopic surveillance for GERD was performed regularly. Conclusion: This questionnaire survey revealed the current status of management of GERD in clinical practice in various Asian countries.

(c) 2019 S. Karger AG, Basel

\section{Introduction}

The Asia-Pacific consensus on the management of gastroesophageal reflux disease (GERD) was originally drawn up in 2004 and was updated with the second revision in 2016. This Consensus focused on proton pump inhibitor (PPI)-refractory reflux disease and Barrett's esophagus (BE) [1]. The Japanese Society of Gastroenterology published evidence-based guidelines for the treatment of GERD in 2015 [2] and revision work is ongoing. Though the management of GERD in Asian regions was assumed to be performed based on these consensuses, the real world of management of GERD in clinical practice is less well-known. The aim of this questionnaire survey was to clarify the current status of management of GERD in clinical practice in Asian regions including Japan, China, Hong Kong, Indonesia, South Korea, the Philippines, Singapore, and Thailand, covering prevalence, diagnosis, treatment, and surveillance interval.

\section{Methods}

This was a questionnaire-based survey conducted by the International Gastrointestinal Consensus Symposium (IGICS). The questionnaire related to GERD management was distributed to members of the IGICS including members from Japan, China, Hong Kong, Indonesia, South Korea, the Philippines, Singapore, and Thailand, and then the members of the IGICS distributed the questionnaire to major institutions in each country. The questionnaire consisted of 32 questions. Following is a summary of the contents of the questionnaire: background of the respondents and institutes; mean numbers of cases of symptomatic erosive GERD (ERD), asymptomatic ERD, nonerosive GERD (NERD), BE $(<3$ $\mathrm{cm}, \geq 3 \mathrm{~cm}$ ), Barrett's adenocarcinoma, and uninvestigated GERD per month; diagnosis; treatment; and examination interval. A patient with uninvestigated GERD was defined as a patient who was diagnosed with GERD based on the patient's symptoms without undergoing upper endoscopy. The contents of the questionnaire are described in the Appendix. The percentages of ERD, NERD, and $\mathrm{BE}$ patients were obtained by dividing the number of cases of ERD, NERD, or BE by the number of cases that underwent endoscopic examination per month. The number of cases of ERD was calculated by adding the number of cases of symptomatic ERD and the number of cases of asymptomatic ERD. The percentage of uninvestigated GERD cases was obtained by dividing the number of cases of uninvestigated GERD by the number of cases that visited the clinic per month. If a percentage was $100 \%$ or more in an institute, the data from the institute were not used in our study because the data were considered to be unreliable. When the answer to a questionnaire item was a wide range of values, the mean value was used (e.g., if a respondent wrote " $5-10$," we used " 7.5 " as the response for that item). The significance of differences among the 7 countries was assessed with the Kruskal-Wallis test, and the significance of differences between the 2 groups of patients with ERD or NERD was assessed with the Mann-Whitney U test. A $p$ value of $<0.05$ was considered to be statistically significant.

\section{Results}

\section{Background of Respondents and Institutes}

Two hundred thirteen respondents who were employed at 213 institutes returned the questionnaire. Among the 213 institutes, 117 institutes were in Japan and 96 were in China, Hong Kong, Indonesia, South Korea, the Philippines, or Singapore. The specialty of most of the respondents was gastroenterology. Other respondents were specialized in gastrointestinal surgery or were general physicians (Table 1). The mean infection rates of Helicobacter pylori among their patients were 35, $16,22,29,32,31$, and $32 \%$ in China, Hong Kong, Indonesia, Japan, South Korea, the Philippines, and Singapore, respectively. There was no significant difference in $H$. pylori infection rate among the countries (online suppl. Fig. 1; for all online suppl. material, see www.karger.com/ doi/10.1159/000504749).

\section{Prevalence of GERD}

The median percentages of patients who were diagnosed with ERD among patients who underwent endoscopic examination at each institute were $28,46,15,16$, 16,17 , and $25 \%$ in China, Hong Kong, Indonesia, Japan, 
Fig. 1. a Percentages of patients who were diagnosed with ERD among patients who underwent endoscopic examination at each institution. Box plots indicate the median (black line), the interquartile range (box), and the smallest and largest values that are not considered outliers. ${ }^{x}$ Value that is considered to be an outlier. There was a significant difference among countries $(p=0.0023)$. b Percentages of patients who were diagnosed with asymptomatic ERD among patients who underwent endoscopic examination at each institution. There was a significant difference among countries $(p=0.0021)$. c Percentages of patients who were diagnosed with non-ERD among patients who underwent endoscopic examination at each institution. There was a significant difference among counties $(p<0.001)$.

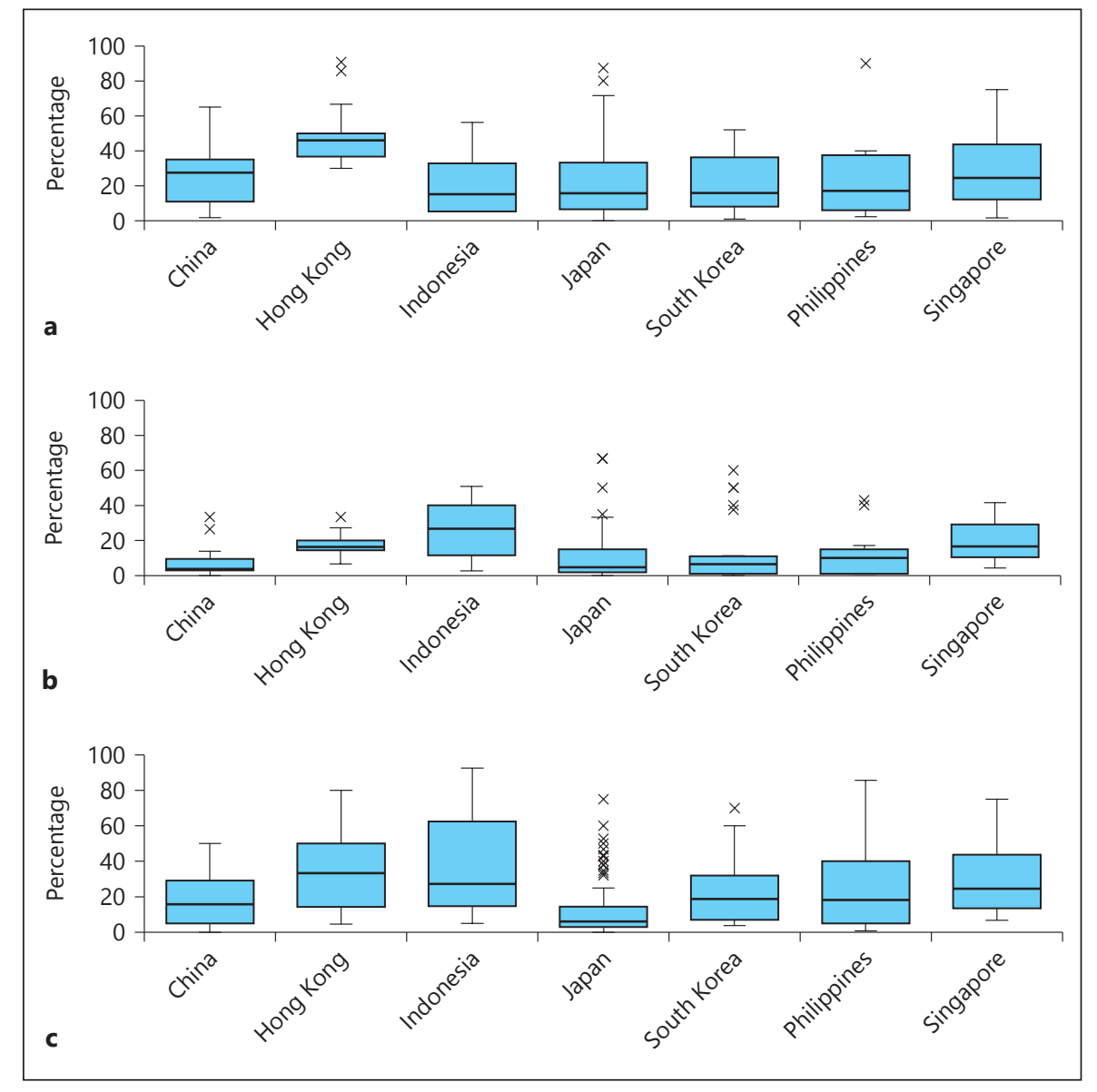

Table 1. Background of the respondents

\begin{tabular}{|c|c|c|c|c|c|}
\hline \multirow[t]{2}{*}{ Country } & \multirow{2}{*}{$\begin{array}{l}\text { Number of } \\
\text { institutes* }\end{array}$} & \multicolumn{4}{|l|}{ Specialty } \\
\hline & & gastroenterology & gastrointestinal surgery & general physician & other \\
\hline China & 18 & 16 & 1 & 1 & 0 \\
\hline Hong Kong & 16 & 16 & 0 & 0 & 0 \\
\hline Indonesia & 20 & 3 & 4 & 10 & 3 \\
\hline Japan & 117 & 105 & 5 & 7 & 0 \\
\hline South Korea & 23 & 23 & 0 & 0 & 0 \\
\hline Philippines & 15 & 15 & 0 & 0 & 0 \\
\hline Singapore & 4 & 4 & 0 & 0 & 0 \\
\hline All countries & 213 & 182 & 10 & 18 & 3 \\
\hline
\end{tabular}

* There was one respondent from each institute.

South Korea, the Philippines, and Singapore, respectively. There was a significant difference among the countries ( $p=0.0023$; Fig. 1). The median percentages of patients who were diagnosed with asymptomatic ERD among patients who underwent endoscopic examination at each institute were 4, 16, 27, 5, 6, 10, and 17\% in China, Hong
Kong, Indonesia, Japan, South Korea, the Philippines, and Singapore, respectively, again showing a significant difference among countries ( $p=0.0021$; Fig. 1$)$. The most frequent indication for upper endoscopy in patients with asymptomatic ERD was the presence of symptoms other than GERD symptoms in China, Hong Kong, Indonesia, 
Fig. 2. The percentage of uninvestigated GERD patients who were diagnosed with GERD only by their symptoms without endoscopy among patients who visited the clinic. ${ }^{\mathrm{x}}$ Mean vaules exceeding 1.5 times the interquartile range from the edge of the box. There was a significant difference among countries $(p<0.001)$.

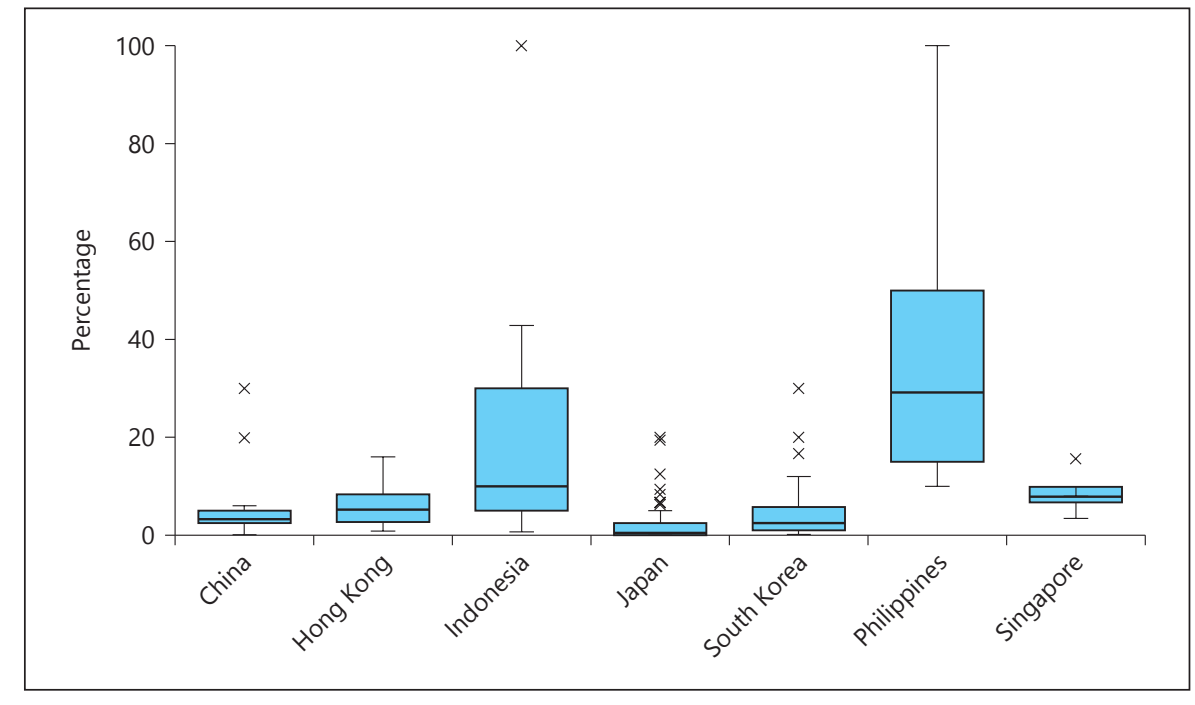

the Philippines, and Singapore and health check or cancer screening in Japan and South Korea. The median percentages of patients who were diagnosed with NERD among patients who underwent endoscopic examination at each institute were $16,33,27,6,19,18$, and $25 \%$ in China, Hong Kong, Indonesia, Japan, South Korea, the Philippines, and Singapore, respectively, showing a significant difference among the countries $(p<0.001$; Fig. 1$)$. There was no significant difference between the percentage of ERD patients and the percentage of NERD patients at each institute in all countries except Japan. In Japan, the percentage of ERD patients was significantly greater than the percentage of NERD patients $(p<0.001)$.

The median percentages of uninvestigated GERD patients who were diagnosed with GERD only by GERD symptoms without endoscopy among patients who visited the clinic were 3, 5, 10, 1, 3, 29, and 8\% in China, Hong Kong, Indonesia, Japan, South Korea, the Philippines, and Singapore, respectively. There was a significant difference among the countries ( $p<0.001$; Fig. 2 ).

The median percentages of patients who were diagnosed with short-segment $\mathrm{BE}(<3 \mathrm{~cm})$ among patients who underwent endoscopic examination at each institute were $6,4,4,9,1,5$, and $1 \%$ in China, Hong Kong, Indonesia, Japan, South Korea, the Philippines, and Singapore, respectively. There was a significant difference among the countries $(p<0.001$; Table 2$)$. The median percentages of patients who were diagnosed with long-segment $\mathrm{BE}$ $(\geq 3 \mathrm{~cm})$ among patients who underwent endoscopic examination at each institute were $3,1,3,0,0,1$, and $1 \%$ in China, Hong Kong, Indonesia, Japan, South Korea, the Philippines, and Singapore, respectively. There was a sig- nificant difference among the countries $(p<0.001$; Table 2 ). The median percentages of patients with Barrett's adenocarcinoma among all cases of esophageal carcinoma at each institute were $17,15,26,5,3,47$, and $40 \%$ in China, Hong Kong, Indonesia, Japan, South Korea, the Philippines, and Singapore, respectively, and the incidence of adenocarcinoma varied significantly among the Asian countries ( $p=0.027$; Table 2$)$.

\section{Diagnosis}

The percentage of respondents who always or often used patient questionnaires on GERD to diagnose GERD was $16,7,60,12,21,27$, and $0 \%$ in China, Hong Kong, Indonesia, Japan, South Korea, the Philippines, and Singapore, respectively (Fig. 3). The percentage of respondents who always or often used the PPI test which included use of a PPI and/or potassium competitive acid blocker (PCAB) to diagnose GERD was $61,27,60,33,48,63$, and $100 \%$ in China, Hong Kong, Indonesia, Japan, South Korea, the Philippines, and Singapore, respectively (Fig. 4). In Japan, the rate of usage of PCAB as the PPI test was $65 \%$, and in the 6 other Asian countries the rate ranged from 0 to $22 \%$. The percentage of respondents who always or often used upper endoscopy to diagnose GERD was 83, $73,35,85,96,47$, and 25\% in China, Hong Kong, Indonesia, Japan, South Korea, the Philippines, and Singapore, respectively (Fig. 5). The percentage of respondents who always or often used patient $\mathrm{pH}$ monitoring to diagnose GERD was 5 and 2\% in Indonesia and Japan, respectively, while the percentage in the other 5 countries was $0 \%$.

Symptoms of heartburn and/or regurgitation were thought to be the most important factor for diagnosing 
Fig. 3. The distribution of frequencies with which the respondents used patient questionnaires to diagnose GERD.

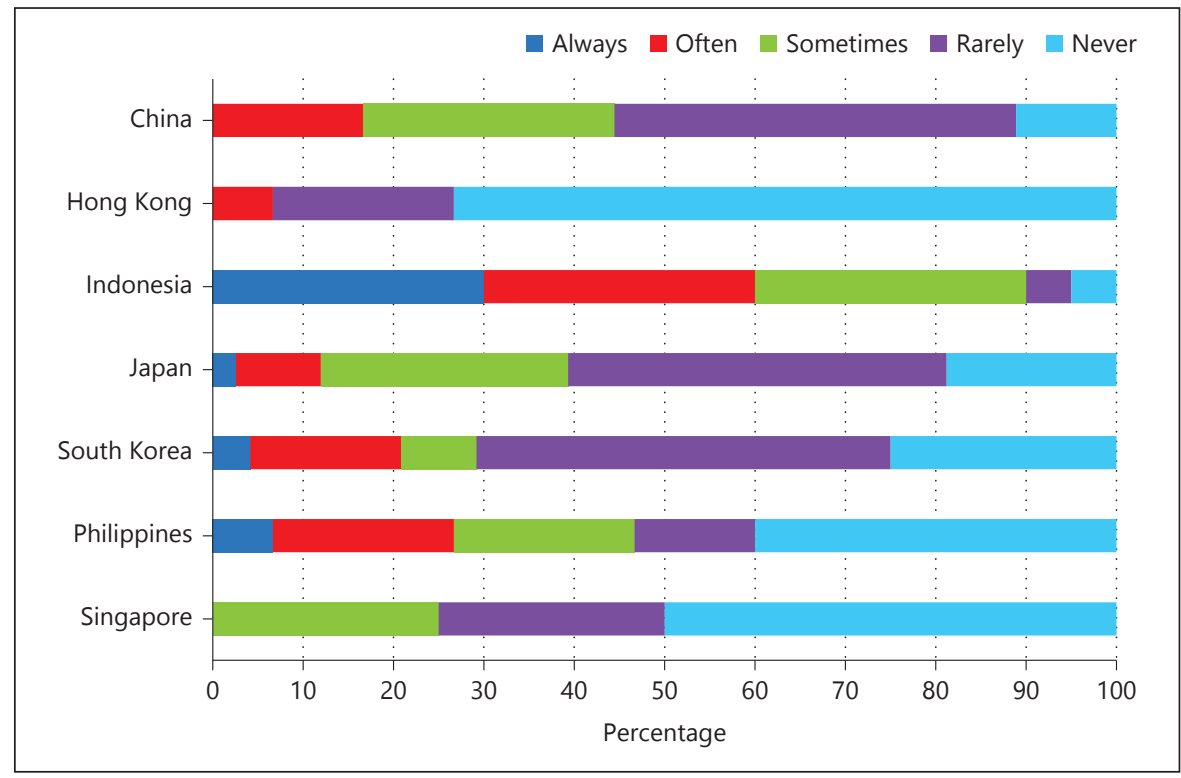

Table 2. Patients who were diagnosed with BE or Barrett's adenocarcinoma

\begin{tabular}{|c|c|c|c|}
\hline & $\begin{array}{l}\text { Short } \mathrm{BE}^{\mathrm{a}}, \% \text {, median } \\
(25 \text { th }-75 \text { th percentile })^{*}\end{array}$ & $\begin{array}{l}\text { Long } \mathrm{BE}^{\mathrm{b}}, \% \text {, median } \\
\text { (25th-75th percentile)* }\end{array}$ & $\begin{array}{l}\text { Barrett's } \mathrm{Ca}^{\mathrm{c}}, \%, \text { median } \\
(25 \text { th-75th percentile)** }\end{array}$ \\
\hline China & $5.8(1.3-16.7)$ & $2.5(0.5-11.1)$ & $16.7(3.8-31.3)$ \\
\hline Hong Kong & $4.0(2-7)$ & $0.8(0.2-1.8)$ & $15.0(0.5-30.3)$ \\
\hline Indonesia & $3.6(2.5-15.7)$ & $2.5(1.4-17)$ & $26.4(0-91.7)$ \\
\hline Japan & $8.9(2.6-20)$ & $0.2(0-0.7)$ & $5(0-10)$ \\
\hline South Korea & $0.7(0.4-2.5)$ & $0.2(0-0.3)$ & $2.9(0-15.4)$ \\
\hline Philippines & $5(2.5-6)$ & $0.8(0.5-3.4)$ & $46.7(0-72.3)$ \\
\hline Singapore & $1(0.3-3.3)$ & $1(0.3-2.5)$ & $40(36.7-60)$ \\
\hline
\end{tabular}

a Patients who were diagnosed with Short BE among patients who underwent endoscopic examination.

${ }^{b}$ Patients who were diagnosed with Long BE among patients who underwent endoscopic examination.

${ }^{c}$ Barrett's adenocarcinoma among all cases of esophageal carcinoma. There was a significant difference among countries $(p<0.001)$.

* There was a significant difference among countries $(p<0.001)$

** There was a significant difference among countries $(p=0.027)$.

$\mathrm{BE}$, Barrett's esophagus; Short BE, short-segment BE ( $<3 \mathrm{~cm})$; Long BE, long-segment BE ( $\geq 3 \mathrm{~cm})$; Barrett's Ca, Barrett's adenocarcinoma.

GERD in every country. The second most important factor for diagnosing GERD was the PPI test in China, Hong Kong, South Korea, and the Philippines, patient questionnaire on symptoms of GERD in Indonesia, and endoscopy in Japan and Singapore (Table 3).

\section{Treatment}

PPI and/or PCAB was prescribed as the therapeutic agent for initial therapy in $>90 \%$ of ERD patients in China, Indonesia, Japan, South Korea, and Singapore, in $88 \%$ of ERD patients in the Philippines, and in $75 \%$ of ERD patients in Hong Kong (Table 4). Alginate was prescribed in around $38 \%$ of ERD patients in Singapore, and prokinetics were prescribed in around $50 \%$ of ERD patients in China, Indonesia, and South Korea. In South Korea and Japan, treatment for GERD patients with grade LA-M without symptoms was less frequently performed than in the other countries. In China, Hong Kong, Indonesia, the Philippines, and Singapore, GERD patients with grade LA-M were a target of treatment even without symptoms (online suppl. Fig. 2). 
Fig. 4. The distribution of frequencies with which the respondents used the PPI test to diagnose GERD.
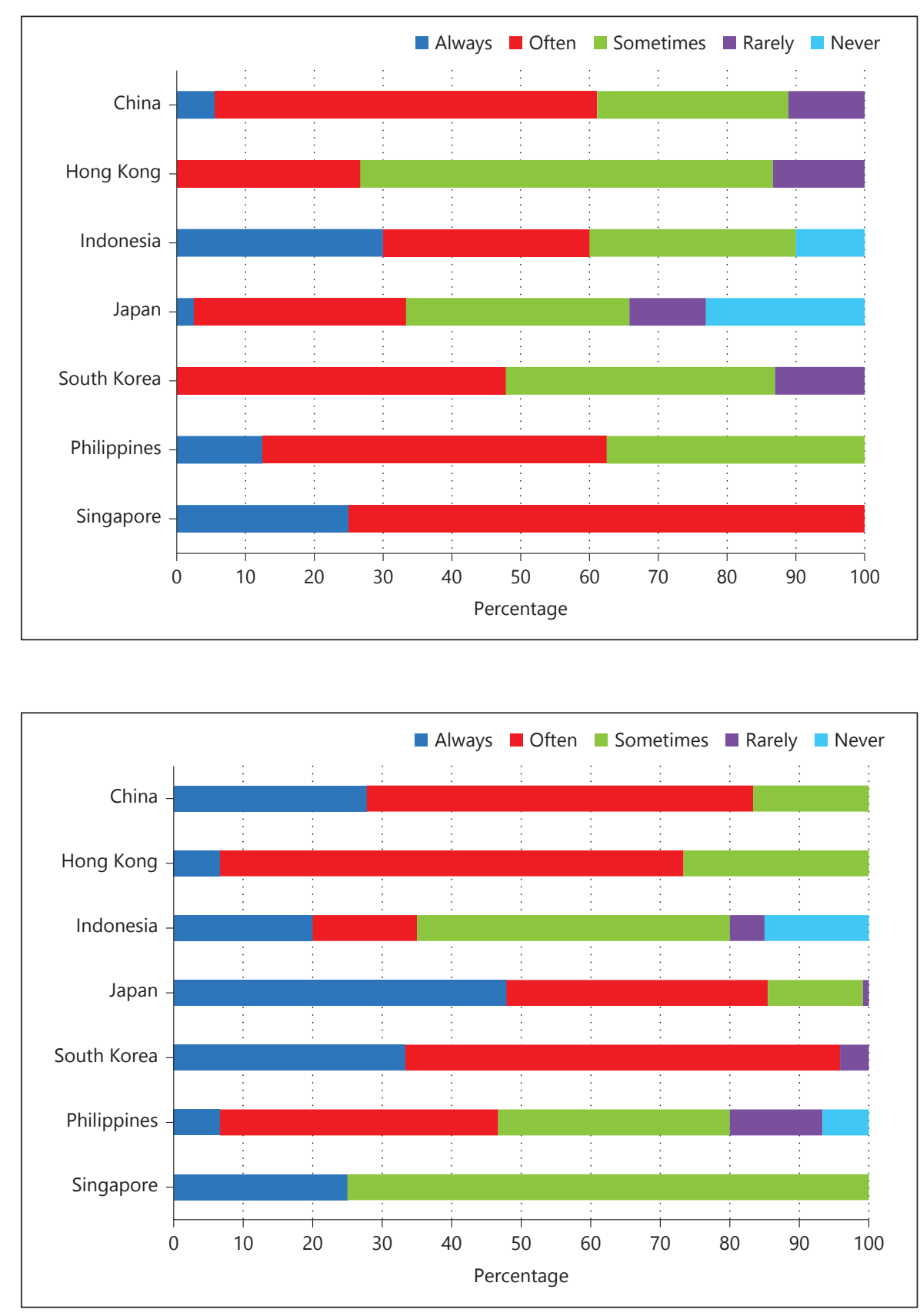

Fig. 5. The distribution of frequencies with which the respondents performed upper endoscopy to diagnose GERD.
PPI or PCAB was prescribed as the therapeutic agent for maintenance therapy of ERD patients with high frequency in all countries, and a half dose of PPI or PCAB was prescribed in around $50 \%$ of the patients who needed maintenance therapy. Histamine 2 receptor antagonists (H2RA) were used in about $20 \%$ of patients needing maintenance therapy in Hong Kong. Prokinetics were not prescribed as maintenance therapy (Table 4).

The mean percentage of respondents who always, often, sometimes, rarely, or never prescribed drugs for
NERD patients in all countries was $12,56,27,5$, and $0 \%$, respectively (online suppl. Fig. 3). PPI or PCAB was prescribed as the therapeutic agent in $>80 \%$ of NERD patients in China, Indonesia, Japan, South Korea, and the Philippines. However, PPI or PCAB was prescribed in about $50 \%$ of NERD patients in Hong Kong and Singapore. In Hong Kong, H2RA was prescribed at the second highest frequency, and in Singapore, alginate was prescribed at the second highest frequency (Table 4). Most NERD patients whose symptoms disappeared after treatment 
Table 3. Most important factors for diagnosing GERD as rated by the respondents

\begin{tabular}{llllll}
\hline Rank & 1 (most important) & 2 & 3 & 4 & 5 (least important) \\
\hline China & Symptoms & PPI test & Endoscopy & Questionnaire & pH monitoring \\
Hong Kong & Symptoms & PPI test & Endoscopy & Questionnaire & pH monitoring \\
Indonesia & Symptoms & Questionnaire & PPI test & Endoscopy & monitoring \\
Japan & Symptoms & Endoscopy & Questionnaire & PPI test & pH monitoring \\
South Korea & Symptoms & PPI test & Endoscopy & Questionnaire & pH monitoring \\
Philippines & Symptoms & PPI test & Endoscopy & Questionnaire & QH monitoring \\
Singapore & Symptoms & Endoscopy & PPI test & pHestionnaire \\
\hline
\end{tabular}

PPI, proton pump inhibitor; GERD, gastroesophageal reflux disease.

were treated by on-demand treatment in all countries (online suppl. Fig. 4).

The percentage of respondents who always or often performed antireflux surgery to treat GERD was 18, 1, and $7 \%$ in Indonesia, Japan, and the Philippines, respectively. In other countries, antireflux surgery was rarely or never performed.

\section{Examination Interval}

The surveillance interval of endoscopy in ERD patients was in most cases from once in 6 months to once in 2 years in China, was in most cases from once in 2 years to once in $>3$ years in Hong Kong, was in most cases once a year in Japan, was once a year or once in 2 years in South Korea, and was in most cases once a year or once in 3 years in the Philippines. The surveillance interval varied from once in 6 months to once in $>3$ years in Indonesia. The surveillance interval was once in 6 months or once in 3 years and more in Singapore (Fig. 6). Around 25\% of the respondents thought that the appropriate interval was $>3$ years for NERD patients in China, Indonesia, and the Philippines. The appropriate interval for NERD patients was thought to be 1 or 2 years in Japan and South Korea. Endoscopy was not frequently performed for NERD patients in Hong Kong and Singapore (Fig. 6).

Regardless of the length of BE, follow-up upper endoscopy was performed at an interval of within 3 years, and endoscopy was performed more frequently in patients with long-segment $\mathrm{BE}$ than in those with short-segment BE (Fig. 7).

\section{Discussion}

This questionnaire survey conducted by the IGICS revealed the current status including the epidemiology, diagnosis, treatment, and surveillance of GERD in various
Asian countries. Moreover, it revealed that the prevalence rate of $H$. pylori infection was $28 \%$ on average in all countries, and management of $H$. pylori infection is still an important issue.

The prevalence of ERD in referred patients and in health screening subjects in a hospital in China was reported to be 51.0 and $23.5 \%$, respectively [3]. Although the prevalence of symptomatic GERD varied significantly by the target population, the prevalence rates were under $10 \%$ in several studies [4-6]. In our results, the percentage of ERD patients among patients who underwent upper endoscopy at each institute ranged from 10 to $46 \%$, and the prevalence of symptomatic GERD, namely uninvestigated GERD, was under $10 \%$ in most Asian countries. It has been known that there are cases of asymptomatic ERD. We previously reported that the frequency of asymptomatic ERD was $11.6 \%$ among ERD patients [7]. In the present survey, the frequency of asymptomatic ERD among patients with ERD in each country varied widely, ranging from 14 to $100 \%$. The data provided in some of the questionnaires were thought to be inappropriate. The prevalence rates of each kind of GERD among patients who underwent upper endoscopy differed significantly among the countries. These differences might have been caused by the availability of endoscopy and the number of subjects. It is known that only one-third of GERD patients have ERD, and others have NERD [8,9]. However, in the present survey, the prevalence of NERD patients among patients who underwent upper endoscopy in each country was $10-30 \%$, and there was no significant difference between the proportion of NERD patients and proportion of ERD patients among patients who underwent endoscopic examination in each country except Japan. In Japan, the proportion of ERD patients was significantly higher than the proportion of NERD patients. Because this survey was a questionnaire and the answers in the questionnaires owed much to each doc- 
Table 4. The median percentage of patients who were treated with the indicated drug as the therapeutic agent in the initial therapy or maintenance therapy for GERD at each institute

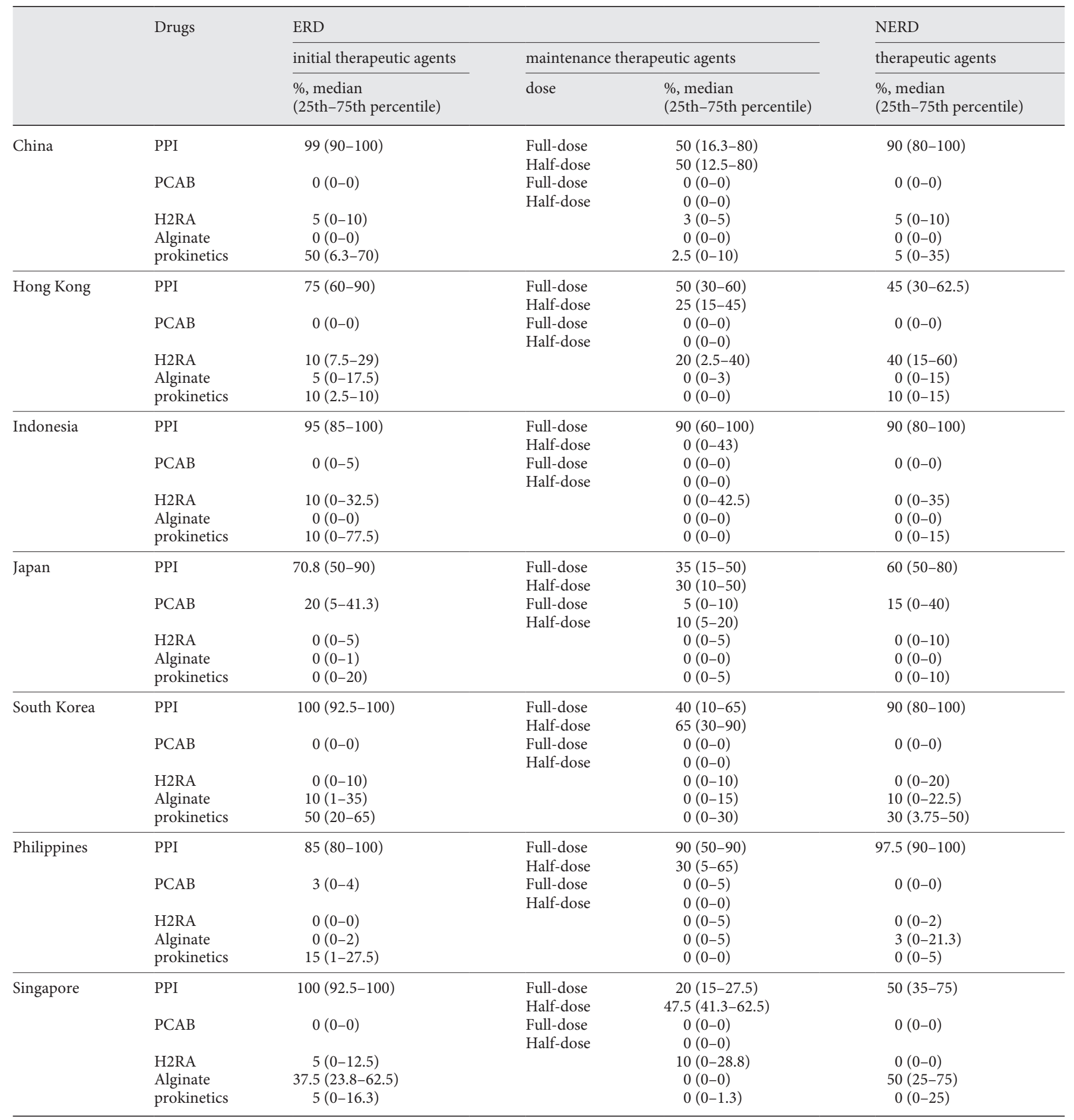

GERD, gastroesophageal reflux disease; ERD, erosive GERD; NERD, non-erosive GERD; PPI, proton pump inhibitor; PCAB, potassium competitive acid blocker; H2RA, histamine 2 receptor antagonists. 
Fig. 6. a The distribution of the surveillance interval of endoscopy in ERD patients. $\mathbf{b}$ The distribution of the surveillance interval of endoscopy in NERD patients.

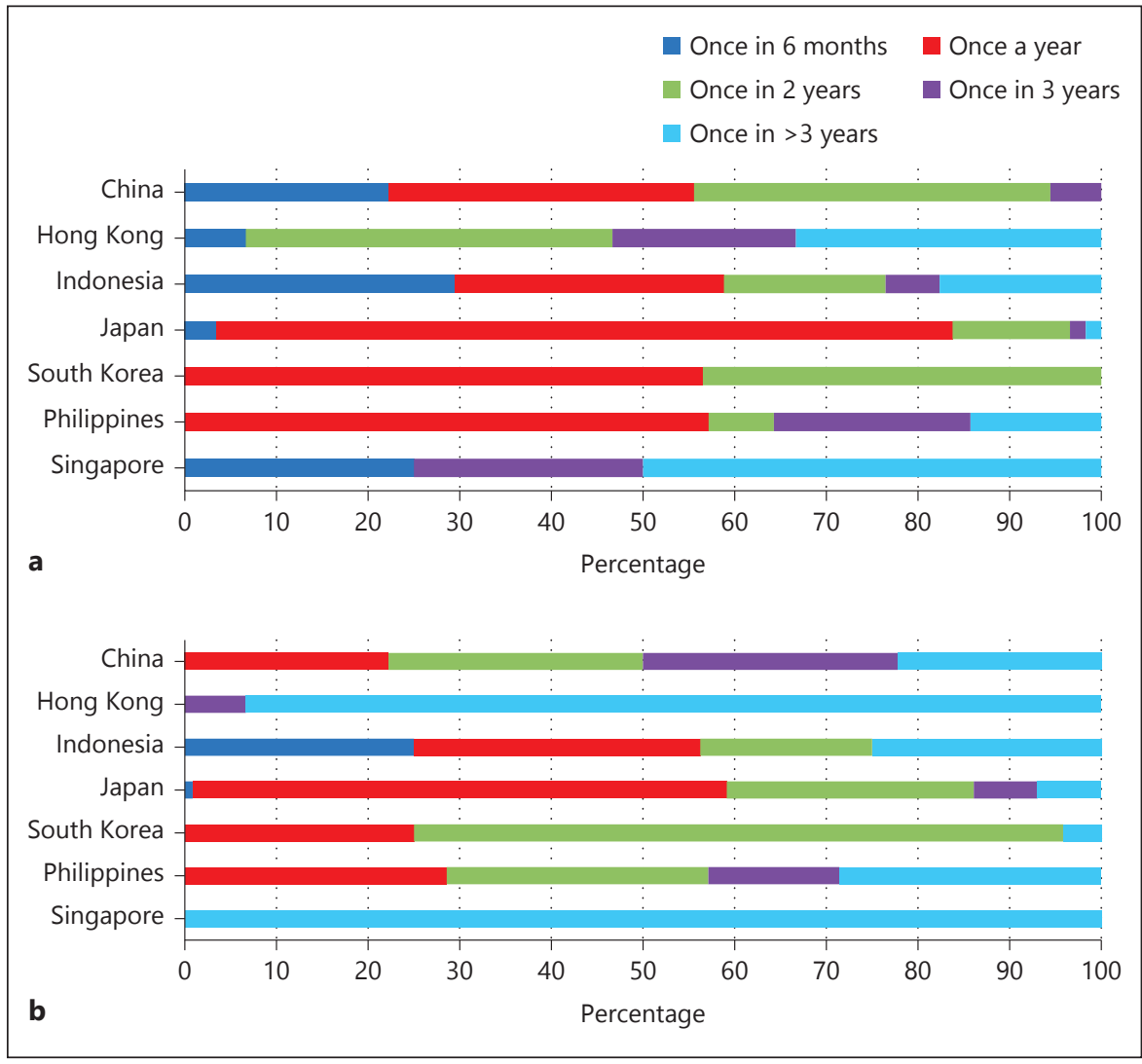

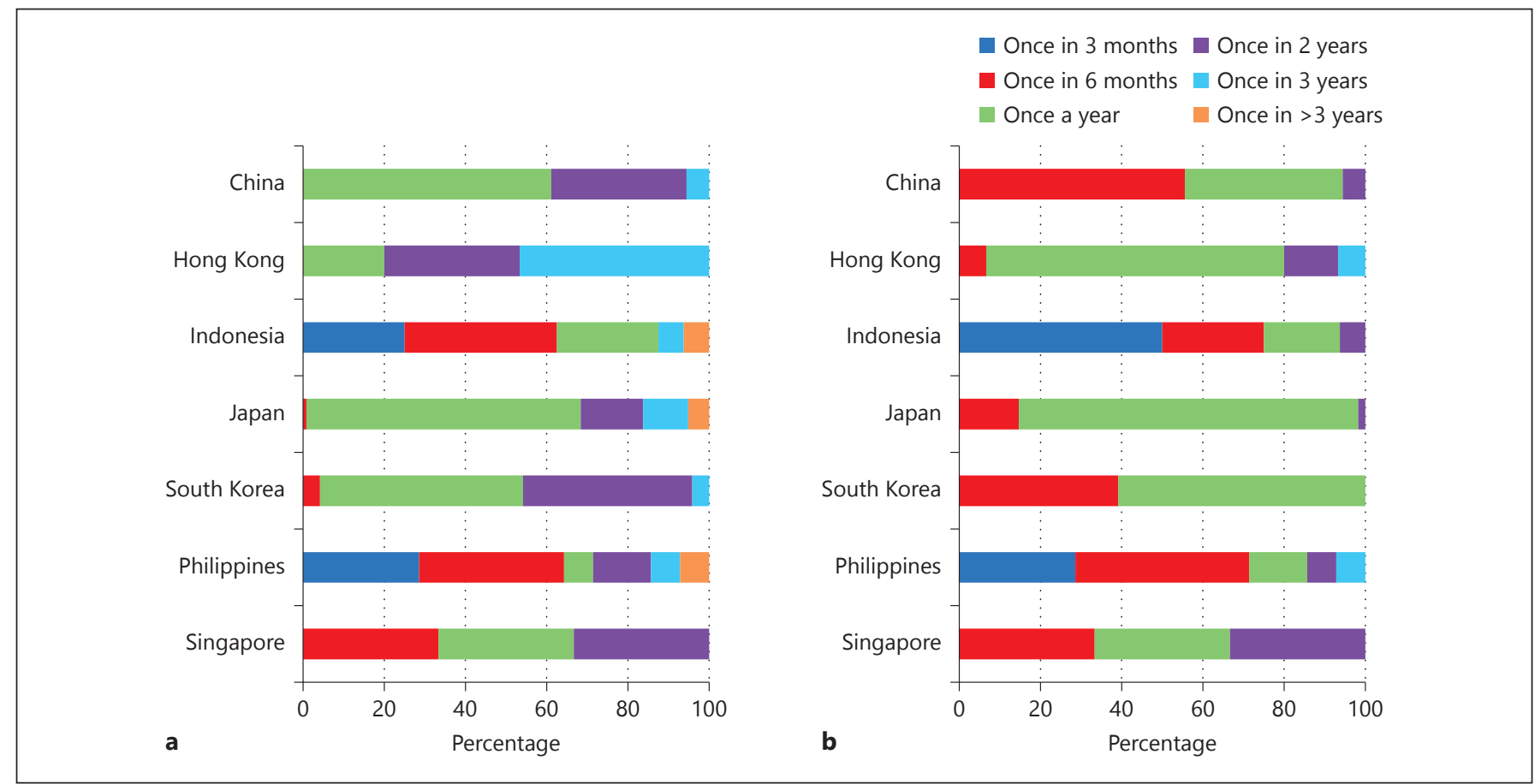

Fig. 7. a The distribution of the surveillance interval of endoscopy in short-segment BE patients. b The distribution of the surveillance interval of endoscopy in long-segment BE patients. 
tor's impressions, the prevalence of NERD patients may differ from the prevalence based on patient questionnaires for GERD symptoms.

The definition of BE has not been standardized yet. Histological confirmation is required to diagnose $\mathrm{BE}$, although the necessity of intestinal metaplasia is controversial $[10,11]$. However, $\mathrm{BE}$ is clinically diagnosed by visual endoscopic appearance. In some studies, the prevalence of BE was determined by endoscopy in symptomatic patients, while in other studies, the prevalence of BE was determined from health screening endoscopy, which includes still inherent selection biases. The Asia-Pacific Consensus recommended that a population prevalence should be determined based on random population endoscopy, but there have only been a few such studies [1] In our survey, the prevalence of $\mathrm{BE}$ was expressed as a percentage of all upper endoscopies performed in each institute. In Japan, the prevalence of short-segment BE is higher than the prevalence of long-segment $\mathrm{BE}$ [2], and the same tendency was also observed in this survey. It is interesting that in other Asian countries there were not much differences in the percentages of short-segment BE and long-segment $\mathrm{BE}$ although there was a difference in prevalence rate of $\mathrm{BE}$ among countries. A longer length of $\mathrm{BE}$ has been associated with a higher cancer risk [12]. Surprisingly, in Indonesia and the Philippines, the percentage of Barrett's adenocarcinoma cases among all cases of esophageal carcinoma was high, while in Indonesia the prevalence rate of long-segment $\mathrm{BE}$ was high, and in the Philippines the rate of long-segment BE was low. In Asia, there may be a unique carcinogenic mechanism, and further studies on the carcinogenesis of BE are required.

There have been several validated GERD patient questionnaires. The sensitivity and specificity of these questionnaires were approximately $70 \%$ [2]. Although these questionnaires are useful tools to diagnose GERD definitely and quantitatively, it takes time to get answers for the questions. Endoscopy may be the first choice to diagnose GERD, in the case of a medical setting in which patients can readily undergo endoscopy. In our survey, the presence of symptoms was the most important for diagnosing GERD. GERD symptoms lower patients' quality of life; therefore, it is important to relieve GERD symptoms immediately. PPIs are useful for relieving GERD symptoms. We previously reported that the percentage of GERD patients with relief of reflux symptoms on day 7 of therapy with a PPI was approximately $60 \%$ [13]. It was stated that the PPI test is also useful to diagnose GERD in the GERD guidelines of 2015 [2]. In our survey, the PPI test was always or often used to diagnose GERD in many

Management of GERD in Asian Countries countries. As a PCAB provides more potent gastric acid suppression [14], the PPI test using a PCAB may be more sensitive for diagnosing GERD.

There is no disagreement about using a PPI as the firstline drug in the treatment of ERD. Interestingly, prokinetics were used in some countries. Khan et al. [15] showed that a combination of pantoprazole and mosapride was more effective than pantoprazole alone in relieving symptoms in patients with ERD, while van Rensburg and Bardhan [16] reported that the addition of cisapride to pantoprazole had no significant additional benefit in relieving symptoms of ERD patients. The usage of prokinetics may be influenced by limitations imposed by the insurance system in each country. PCAB is more effective in healing erosive esophagitis and in relieving GERD symptoms than PPIs [17-20]. Unfortunately, $\mathrm{PCAB}$ is used in only a few countries. It became clear through this survey that $\mathrm{PCAB}$ was frequently used for ERD treatment in Japan. PPI maintenance therapy at full dose or half dose is recommended for patients with severe ERD, and PPI on-demand therapy is recommended for patients with mild ERD in the GERD guidelines of 2015 [2]. In our survey, half dose of PPI or PCAB was prescribed for around $50 \%$ of the patients who needed maintenance therapy. It is generally believed that $H$. pylori infection has a protective role against GERD in Asia [21]. In our survey, the $H$. pylori infection rate was still high. The half-dose of a PPI may prevent relapse of mucosal damage in patients with $H$. pylori infection, but not in patients who are negative for $H$. pylori infection.

In a meta-analysis to evaluate the efficacy of PPI treatment for NERD, PPIs were superior to H2RAs in symptomatic relief and there were no obvious differences in efficacy among PPI types [22]. However, PPI has been thought to be less successful in relieving symptoms in NERD patients than in ERD patients [23]. In our survey, the main treatment for NERD was PPIs, while H2RA, alginate, and prokinetics were also used. The lower responses to PPI in NERD patients may be caused by the existence of other factors related to symptom generation in NERD patients besides acid [24]. On-demand therapy with a PPI has been proposed for patients with NERD who responded to a PPI in the initial therapy in the GERD guidelines of 2015 [2]. Previously, we compared the efficacy of continuous therapy with on-demand therapy in GERD patients in clinical practice [25]. There was no significant difference between the continuous group and on-demand group in the percentage of patients who were symptom-free. Ondemand therapy would be sufficient as long-term followup therapy, since NERD is defined by the presence of 
symptoms [26]. In our survey, on-demand therapy was most frequently selected; therefore, prescriptions were written when symptoms occurred in many countries.

The purposes of endoscopic surveillance are to confirm healing of reflux esophagitis and to detect Barrett's adenocarcinoma in its early stages. Among patients with mild reflux esophagitis who did not receive medical therapy, only $10.5 \%$ of patients progressed to more severe forms of reflux esophagitis and $60.0 \%$ of patients relapsed without disease progression [27]. According to the most recent report from Japan, the 1-year incidence rate of Barrett's adenocarcinoma in patients with long-segment $\mathrm{BE}$ was calculated to be $1.2 \%$ [28]. Endoscopic surveillance to detect dysplasia is recommended and a 3-to 5-year interval is suggested in BE patients without dysplasia in Western guidelines $[11,29,30]$. Our survey showed that although endoscopy is performed more frequently for patients with long-segment $\mathrm{BE}$ than for patients with shortsegment BE, endoscopic surveillance was performed at intervals of within 3 years in Asian countries regardless of the length of BE. Moreover, endoscopy was also performed at intervals within 3 years in many ERD patients. In Asian countries, endoscopic surveillance for GERD was performed regularly.

In conclusion, this questionnaire survey revealed the current status of management of GERD in various Asian countries. The frequencies of ERD, NERD, BE, and uninvestigated GERD varied significantly among Asian countries. The most important factor in diagnosing GERD was the presence of symptoms in all countries. PPI is the most commonly prescribed drug to treat GERD in all countries. Endoscopic surveillance for GERD was performed regularly.

\section{Acknowledgment}

The authors thank all doctors who participated in this survey and also the office personnel of the IGICS for their secretarial work.

\section{Statement of Ethics}

An ethical approval was not required or obtained, because this consensus report was a questionnaire-based survey.

\section{Disclosure Statement}

The authors have no conflicts of interest to declare.

\section{Funding Sources}

The authors have no funding sources.

\section{Author Contributions}

Drs. Akihito Nagahara and Mariko Hojo designed the study, collected and analyzed the questionnaire, and drafted the article. Drs. Ki-Baik Hahm, Ryuichi Iwakiri, Toshio Watanabe, Abdul Aziz Rani, Qi Zhu, Francis K.L. Chan, Jose D. Sollano, Takeshi Kamiya, Satoru Yamaguchi, Satoshi Motoya, Kwong Ming Fock, Shin Fukudo, Udom Kachintorn, Hidekazu Suzuki, and Kazunari Murakami reviewed and aggregated the questionnaire.

\section{Appendix}

In Questionnaire on management of GERD

Please check the appropriate box or specify your answer in the blank spaces.

\section{General}

1 . What is your country?

$\square$ China

$\square$ Hong Kong

$\square$ Indonesia

$\square$ Japan

$\square$ Korea

$\square$ Philippines

$\square$ Thailand

$\square$ Singapore

$\square$ Other ( )

2. What is your specialty?

$\square$ Gastroenterology

$\square$ Gastrointestinal surgery

$\square$ General physician

$\square$ Other ( )

3. How many patients per month visit the clinic in your department on average?

( cases/month)

4. What percentage of patients who are treated in your department are infected with $H$. pylori?

( \%)

5. How many patients undergo upper endoscopy per month in your department on average?

( cases/month)

Please answer the following No. 6--11 questions about patients who underwent endoscopy.

6. How many symptomatic ERD patients per month visit the clinic in your department on average?

( cases/month)

7. What are the upper endoscopy indications for patients with asymptomatic ERD?

( )

8. How many asymptomatic ERD patients per month visit the clinic in your department on average?

( cases/month) 
9. How many NERD patients per month visit the clinic in your department on average?

( cases/month)

10. How many patients with long-segment Barrett's esophagus $(\mathrm{BE} ; \geq 3 \mathrm{~cm})$ per month visit the clinic in your department on average?

(cases/month)

11. How many patients with short-segment $\mathrm{BE}(<3 \mathrm{~cm})$ per month visit the clinic in your department on average?

( cases/month)

12. How many patients with esophageal carcinoma per year visit the clinic in your department on average?

( All cases of esophageal carcinoma cases/year)

( Adenocarcinoma and Barrett's carcinoma cases/year)

13. How many uninvestigated GERD patients* per month visit the clinic in your department on average?

( cases/month)

* Patients who are diagnosed with GERD only by GERD symptoms without endoscopy.

Diagnosis

14. How frequently do you use patient questionnaires on GERD to diagnose GERD?

$\square$ Always

$\square$ Often

$\square$ Sometimes

$\square$ Rarely

$\square$ Never

15. How frequently do you perform the PPI test** to diagnose GERD?

$\square$ Always

$\square$ Often

$\square$ Sometimes

$\square$ Rarely

$\square$ Never

Have you ever used PCAB as the PPI test?

$\square$ Yes

$\square$ No

** The PPI test includes use of a PPI and/or PCAB.

16. How frequently do you perform upper endoscopy to diagnose GERD?

$\square$ Always

$\square$ Often

$\square$ Sometimes

$\square$ Rarely

$\square$ Never

Do you use the Los Angeles classification at the time of diagnosis of ERD?

$\square$ Yes

$\square$ No

If you do not use the Los Angeles classification, please provide the classification that you use.

( )

17. How frequently do you perform $\mathrm{pH}$ monitoring to diagnose GERD?

$\square$ Always

$\square$ Often

$\square$ Sometimes

$\square$ Rarely

$\square$ Never
18. What do you think is the most important for diagnosing GERD? Please rank the items from 1 (most important) to 5 (least important).

( ) Symptoms of heartburn and/or regurgitation

( ) Patient questionnaire on symptoms of GERD

( ) PPI test

( ) Endoscopy

( ) $\mathrm{pH}$ monitoring

19. How frequently do you perform the following imaging examinations other than upper endoscopy to make the differential diagnosis of GERD?

a. Abdominal sonography

$\square$ Always

$\square$ Often

$\square$ Sometimes

$\square$ Rarely

$\square$ Never

b. Abdominal computer tomography (CT)

$\square$ Always

$\square$ Often

$\square$ Sometimes

$\square$ Rarely

$\square$ Never

c. Upper gastrointestinal series

$\square$ Always

$\square$ Often

$\square$ Sometimes

$\square$ Rarely

$\square$ Never

d. Colonoscopy

$\square$ Always

$\square$ Often

$\square$ Sometimes

$\square$ Rarely

$\square$ Never

e. Lower gastrointestinal series

$\square$ Always

$\square$ Often

$\square$ Sometimes

$\square$ Rarely

$\square$ Never

Treatment

Initial treatment

20. How frequently do you prescribe the following drugs as therapeutic agents for ERD? Please express the frequency of use of each agent as a percentage.

PPI ( \%)
PCAB ( \%)
H2RA $(\%)$

Alginate $(\%)$

Gastroprokinetic agents ( \%)

Others ( ) ( \%) 
21. Grades that are a target for treatment.

a. What grade is a target for treatment in GERD patients with symptoms? Please select all grades that apply.

$\square \mathrm{LA}-\mathrm{M}$

$\square$ LA-A

$\square$ LA-B

$\square \mathrm{LA}-\mathrm{C}$

$\square$ LA-D

b. What grade is a target for treatment in GERD patients without symptoms? Please select all grades that apply.

$\square$ LA-M
$\square$ LA-A
$\square$ LA-B
$\square$ LA-C
$\square$ LA-D

\section{Maintenance treatment}

22. How frequently do you prescribe the following drugs as maintenance therapy for ERD? Please express the frequency of use of each drug as a percentage.

Full-dose PPI ( \%)

Half-dose PPI ( \%)

Full-dose PCAB ( \%)

Half-dose PCAB ( \%)

H2RA ( \%)

Alginate ( \%)

Gastroprokinetic agents ( \%)

Others ( , ) ( \%)

NERD

23. How frequently do you prescribe drugs for the treatment of NERD?

$\square$ Always

$\square$ Often

$\square$ Sometimes

$\square$ Rarely

$\square$ Never

24. How frequently do you prescribe the following drugs as therapeutic agents for NERD? Please express the frequency of use of each drug as a percentage.

PPI ( \%)

PCAB ( \%)

H2RA ( \%)

Alginate ( \%)

Gastroprokinetic agents ( \%)

Others ( ) ( \%)

25. What do you do for NERD patients whose symptoms have disappeared after treatment?

$\square$ Follow-up without medicine

$\square$ On-demand treatment

$\square$ Continuous treatment

How frequently do you prescribe the following drugs, if you chose on-demand or continuous treatment? Please express the frequency of use of each drug as a percentage.

PPI ( \%)

$\operatorname{PCAB}(\%)$

H2RA ( \%)

Alginate ( \%)

Gastroprokinetic agents ( \%)

Others ( ) ( \%)
Surgical treatment

26. How frequently do you perform antireflux surgery for the treatment of GERD?

$\square$ Always

$\square$ Often

$\square$ Sometimes

$\square$ Rarely

$\square$ Never

How many patients undergo antireflux surgery per year in your department on average?

( cases/year)

Examination interval of GERD

27. How frequently do you think endoscopic examinations should be performed in patients with ERD?

$\square$ Once in 6 months

$\square$ Once a year

$\square$ Once in 2 years

$\square$ Once in 3 years

$\square$ Once in $>3$ years

28. How frequently do you think endoscopic examinations should be performed in patients with NERD?

$\square$ Once in 6 months

$\square$ Once a year

$\square$ Once in 2 years

$\square$ Once in 3 years

$\square$ Once in $>3$ years

Barrett's esophagus (BE)

29. Among patients with BE, to which patients do you prescribe acid-suppressive agents (PPI, etc.)? Please select all that apply.

$\square$ All patients with BE regardless of length

$\square$ All patients with long-segment BE

$\square$ Patients with long-segment BE and reflux esophagitis

$\square$ All patients with short-segment BE

$\square$ Patients with short-segment $\mathrm{BE}$ and reflux esophagitis

30. How frequently do you think endoscopic examinations should be performed in patients with long-segment BE?

$\square$ Once in 3 months

$\square$ Once in 6 months

$\square$ Once a year

$\square$ Once in 2 years

$\square$ Once in 3 years

$\square$ Once in $>3$ years

31. How frequently do you think endoscopic examinations should be performed in patients with short-segment BE?

$\square$ Once in 3 months

$\square$ Once in 6 months

$\square$ Once a year

$\square$ Once in 2 years

$\square$ Once in 3 years

$\square$ Once in $>3$ years

32. Among patients with $\mathrm{BE}$, of which patients do you consider to take the biopsy specimens from the site of BE?

$\square$ All patients with BE regardless of length

$\square$ All patients with long-segment BE

$\square$ Patients with BE regardless of length and reflux esophagitis

$\square$ Patients with long-segment BE and reflux esophagitis

$\square$ Others ( ) 


\section{References}

1 Fock KM, Talley N, Goh KL, Sugano K, Katelaris P, Holtmann G, et al. Asia-Pacific consensus on the management of gastro-oesophageal reflux disease: an update focusing on refractory reflux disease and Barrett's oesophagus. Gut. 2016 Sep;65(9):1402-15.

2 Iwakiri K, Kinoshita Y, Habu Y, Oshima T, Manabe N, Fujiwara Y, et al. Evidence-based clinical practice guidelines for gastroesophageal reflux disease 2015. J Gastroenterol. 2016 Aug;51(8):751-67.

3 Chen MJ, Lee YC, Chiu HM, Wu MS, Wang HP, Lin JT. Time trends of endoscopic and pathological diagnoses related to gastroesophageal reflux disease in a Chinese population: eight years single institution experience. Dis Esophagus. 2010 Apr;23(3): 201-7.

4 Bhatia SJ, Reddy DN, Ghoshal UC, Jayanthi V, Abraham P, Choudhuri G, et al. Epidemiology and symptom profile of gastroesophageal reflux in the Indian population: report of the Indian Society of Gastroenterology Task Force. Indian J Gastroenterol. 2011 May; 30(3):118-27.

5 He J, Ma X, Zhao Y, Wang R, Yan X, Yan H, et al. A population-based survey of the epidemiology of symptom-defined gastroesophageal reflux disease: the Systematic Investigation of Gastrointestinal Diseases in China. BMC Gastroenterol. 2010 Aug;10(1):94.

6 Zou D, He J, Ma X, Chen J, Gong Y, Man X, et al. Epidemiology of symptom-defined gastroesophageal reflux disease and reflux esophagitis: the systematic investigation of gastrointestinal diseases in China (SILC). Scand J Gastroenterol. 2011 Feb;46(2):133-41.

7 Nagahara A, Hojo M, Asaoka D, Sasaki H, OguroM,MoriH, etal.Clinicalfeatureofasymptomatic reflux esophagitis in patients who underwent upper gastrointestinal endoscopy. J Gastroenterol Hepatol. 2012 Apr;27 Suppl 3:53-7.

8 Savarino E, Marabotto E, Bodini G, Pellegatta G, Coppo C, Giambruno E, et al. Epidemiology and natural history of gastroesophageal reflux disease. Minerva Gastroenterol Dietol. 2017 Sep;63(3):175-83.

9 Fujiwara Y, Arakawa T. Epidemiology and clinical characteristics of GERD in the Japanese population. J Gastroenterol. 2009;44(6): 518-34.

10 Fitzgerald RC, di Pietro M, Ragunath K, Ang Y, Kang JY, Watson P, et al.; British Society of Gastroenterology. British Society of Gastroenterology guidelines on the diagnosis and management of Barrett's oesophagus. Gut. 2014 Jan;63(1):7-42.
11 Shaheen NJ, Falk GW, Iyer PG, Gerson LB; American College of Gastroenterology. ACG Clinical Guideline: Diagnosis and Management of Barrett's Esophagus. Am J Gastroenterol. 2016 Jan;111(1):30-50.

12 Corley DA, Levin TR, Habel LA, Weiss NS, Buffler PA. Surveillance and survival in Barrett's adenocarcinomas: a population-based study. Gastroenterology. 2002 Mar;122(3):633-40.

13 Nagahara A, Suzuki T, Nagata N, Sugai N, Takeuchi Y, Sakurai K, et al. A multicentre randomised trial to compare the efficacy of omeprazole versus rabeprazole in early symptom relief in patients with reflux esophagitis. J Gastroenterol. 2014 Dec;49(12): 1536-47.

14 Akiyama J, Hosaka H, Kuribayashi S, Moriyasu S, Hisada Y, Okubo H, et al. Efficacy of Vonoprazan, a Novel Potassium-Competitive Acid Blocker, in Patients with Proton Pump Inhibitor-Refractory Acid Reflux. Digestion. DOI: $10.1159 / 000497775$.

15 Khan M, Santana J, Donnellan C, Preston C, Moayyedi P. Medical treatments in the short term management of reflux oesophagitis. Cochrane Database Syst Rev. 2007 Apr;(2):CD003244.

16 van Rensburg CJ, Bardhan KD. No clinical benefit of adding cisapride to pantoprazole for treatment of gastro-oesophageal reflux disease. Eur J Gastroenterol Hepatol. 2001 Aug;13(8):909-14.

17 Ashida K, Sakurai Y, Hori T, Kudou K, Nishimura A, Hiramatsu N, et al. Randomised clinical trial: vonoprazan, a novel potassiumcompetitive acid blocker, vs. lansoprazole for the healing of erosive oesophagitis. Aliment Pharmacol Ther. 2016 Jan;43(2):240-51.

18 Miyazaki H, Igarashi A, Takeuchi T, Teng L, Uda A, Deguchi H, et al. Vonoprazan versus proton-pump inhibitors for healing gastroesophageal reflux disease: A systematic review. J Gastroenterol Hepatol. 2019 Aug; 34(8):1316-28.

19 Asaoka D, Nagahara A, Hojo M, Matsumoto K, Ueyama H, Matsumoto K, et al. Efficacy of a potassium-competitive acid blocker for improving symptoms in patients with reflux esophagitis, non-erosive reflux disease, and functional dyspepsia. Biomed Rep. 2017 Feb; 6(2):175-80.

20 Oshima T, Arai E, Taki M, Kondo T, Tomita T, Fukui H, et al. Randomised clinical trial: vonoprazan versus lansoprazole for the initial relief of heartburn in patients with erosive oesophagitis. Aliment Pharmacol Ther. 2019 Jan;49(2):140-6.
$21 \mathrm{Wu}$ JC. Does Helicobacter pylori infection protect against esophageal diseases in Asia? Indian J Gastroenterol. 2011 Jul;30(4):14953.

22 Zhang JX, Ji MY, Song J, Lei HB, Qiu S, Wang $\mathrm{J}$, et al. Proton pump inhibitor for non-erosive reflux disease: a meta-analysis. World J Gastroenterol. 2013 Dec;19(45):8408-19.

23 Gardner JD, Gallo-Torres H, Sloan S, Robinson M, Miner PB. The basis for the decreased response to proton pump inhibitors in gastrooesophageal reflux disease patients without erosive oesophagitis. Aliment Pharmacol Ther. 2003 Nov;18(9):891-905.

24 Nagahara A, Miwa H, Minoo T, Hojo M, Kawabe M, Osada T, et al. Increased esophageal sensitivity to acid and saline in patients with nonerosive gastro-esophageal reflux disease. J Clin Gastroenterol. 2006 Nov-Dec;40(10):891-5.

25 Nagahara A, Hojo M, Asaoka D, Sasaki H, Watanabe S. A randomized prospective study comparing the efficacy of on-demand therapy versus continuous therapy for 6 months for long-term maintenance with omeprazole 20 $\mathrm{mg}$ in patients with gastroesophageal reflux disease in Japan. Scand J Gastroenterol. 2014 Apr;49(4):409-17.

26 Martinez SD, Malagon IB, Garewal HS, Cui $H$, Fass R. Non-erosive reflux disease (NERD) - acid reflux and symptom patterns. Aliment Pharmacol Ther. 2003 Feb;17(4):537-45.

27 Manabe N, Yoshihara M, Sasaki A, Tanaka S, Haruma K, Chayama K. Clinical characteristics and natural history of patients with lowgrade reflux esophagitis. J Gastroenterol Hepatol. 2002 Sep;17(9):949-54

28 Matsuhashi N, Sakai E, Ohata K, Ishimura N, Fujisaki J, Shimizu T, et al. Surveillance of patients with long-segment Barrett's esophagus: A multicenter prospective cohort study in Japan. J Gastroenterol Hepatol. 2017 Feb;32(2): 409-14.

29 Evans JA, Early DS, Fukami N, Ben-Menachem T, ChandrasekharaV, ChathadiKV, etal.;ASGE Standards of Practice Committee; Standards of Practice Committee of the American Society for Gastrointestinal Endoscopy. The role of endoscopy in Barrett's esophagus and other premalignant conditions of the esophagus. Gastrointest Endosc. 2012 Dec;76(6):1087-94.

30 Spechler SJ, Sharma P, Souza RF, Inadomi JM, Shaheen NJ; American Gastroenterological Association. American Gastroenterological Association medical position statement on the management of Barrett's esophagus. Gastroenterology. 2011 Mar;140(3):108491. 